\title{
Echocardiographic features of free floating thrombus mimicking right ventricular myxoma
}

Sir,

I read with interest the case report by Shiu and Abrams (1983; 49: 612-4). I have seen two similar cases of "consecutive thrombus" involving the right heart in patients with pulmonary embolism which had similar echocardiographic appearances. Three echocardiographic features which should suggest the diagnosis of free floating thrombus and be of assistance in differentiating them from right heart tumours are: (a) their serpentine or chaotic movement on cross sectional echo; (b) their lack of attachment to the atrial septum of tricuspid valve; and (c) repeat echocardiographic examination, minutes to hours later, shows disappearance of the thrombus from the right heart associated with clinical deterioration owing to intractable and progressive right heart failure as the thrombus escapes the right heart cavities and wholly or partially occludes the pulmonary artery.

Martin G St John Sutton, Cardiovascular Section, Department of Medicine, Hospital of the University of Pennsylvania, Philadelphia 19104, USA.
This letter was shown to the authors, who reply as follows:

Sir,

We appreciate Dr Sutton's interest in our case report on the cross sectional features of free floating thrombus in the right ventricle in a patient with massive pulmonary embolus.

Dr Sutton's first two points on suggestive features of free floating thrombus were discussed in our paper as was the need for follow up studies. As to whether embolisation of a right ventricular clot would be associated with clinical deterioration, this would surely depend on the precariousness of the patient's pre-existing haemodynamic status.

MF Shiu,

LD Abrams,

Department of Cardiology and Cardiac Surgery, Queen Elizabeth Hospital, Birmingham B15 2TH.

\section{Notices}

\section{British Cardiac Society}

The Annual General Meeting for 1984 will take place in Leicester on 11 and 12 April 1984, and the closing date for receipt of abstracts will be 3 January 1984 .

The Autumn Meeting in 1984 will be held on 3 and 4 December 1984, and the closing date for receipt of abstracts will be 15 August 1984 .

\section{Current concepts in echocardiography}

A four day course on current concepts in echocardiography will take place on 3-6 April 1984 at St George's Hospital Medical School. Details from: The Postgraduate Secretary, St George's Hospital Medical School, Cranmer Terrace, London SW17 0RE.
Intensive care and emergency medicine

A fourth international symposium on intensive care and emergency medicine will be held at the Institute of Sociology of the Free University of Brussels, Belgium, on 28-30 March 1984. Further details may be obtained from: Dr J-L Vincent, Erasme Hospital, Route de Lennik 808, 1070 Brussels, Belgium. 